\title{
Orchestrating Inquiry-Based Learning Spaces: an Analysis of Teacher Needs
}

\author{
María Jesús Rodríguez-Triana, Adrian Holzer, Andrii Vozniuk, and Denis Gillet \\ School of Engineering, École Polytechnique Fédérale de Lausanne, Switzerland \\ \{maria.rodrigueztriana, adrian.holzer, andrii.vozniuk, \\ denis.gillet\}eepfl.ch http://react.epfl.ch/
}

\begin{abstract}
The European Go-Lab project offers Inquiry Learning Spaces (ILSs) as open educational resources to support Inquiry-based Learning (IBL). To successfully exploit ILSs and implement IBL, proper support for orchestration is needed. Researchers have highlighted the complexity of orchestrating Technology Enhanced Learning (TEL) scenarios and the need for supporting participants in this endeavour. In this paper, we address this issue by analyzing the teacher needs when orchestrating IBL and relying on ILSs. Concretely, we have carried out a survey-based study with 23 expert teachers in IBL and four in-depth case studies in authentic classroom scenarios with 2 teachers. The results lead us to a set of needs to be covered regarding the design of the ILS, the learning process and the learning outcomes.
\end{abstract}

Keywords: Orchestration, Inquiry-Based Learning, Teachers

\section{Introduction}

In inquiry learning the main goal is to encourage students to develop their own questioning, figure out their own responses by making proper hypotheses and designing proper experiments, and reflect on the observations. Inquiry learning can be a successful pedagogical approach, provided that effective support is offered to the students [7]. Support can be implemented at various levels. First, activities can be structured in successive inquiry phases (e.g. Orientation, Conceptualization, Investigation, Conclusion, Discussion). Second, within each phase, scaffolding tools can support activities. For instance a concept mapping scaffolding tool can support the Conceptualization phase. Third, relevant cues can be given to the students when necessary. Additionally, in order to conduct a successful learning activity, other authors have highlighted the challenge of providing stakeholders with technologies that support orchestration [14] [18]. Since teachers play a crucial role in the orchestration of learning activities, it is necessary to analyze what their orchestration needs are in a IBL scenario to help them in this endeavour.

The Go-Lab European project ${ }^{1}$ is an ongoing initiative that precisely aims at providing this kind of support to promote inquiry learning at school for STEM education via inquiry learning spaces - ILSs for short. In order to overcome the complexity of orchestration in IBL, this paper addresses the following research question: What are the

\footnotetext{
${ }^{1}$ Go-Lab project: http: //www.go-lab-project.eu
} 
teacher orchestration needs when using ILSs? To better understand this question, this paper presents a survey-based study with 23 expert teachers in IBL and four in-depth case studies in authentic classroom scenarios with 2 teachers.

The remainder of this paper is structured as follows. Section 2 provides an overview of the related work done in orchestration of IBL. Section 3 presents the concept of the ILS in Go-Lab. Section 4 describes the research methodology that guided the studies covered in Section 5 and Section 6. Finally, Section 7 discusses the main findings and Section 8 wraps up with the conclusions.

\section{Related Work}

In the field of TEL, the metaphor of orchestrating learning is frequently used to reference the challenges that teachers, students, parents, institution, etc. face throughout the learning scenario lifecycle [4]. It covers aspects such as design, management, adaptation and assessment of learning activities, aligning the resources available to achieve the maximum learning effect, informed by theory while complying pragmatically with the contextual constraints of the setting [13]. Technological solutions can facilitate this endeavour by providing adequate support [10]. E.g., Dyckhoff et al. [5] identified a list of teachers information needs to be addressed. The resulting categories were related to the learning process (at individual, group and course level), the learning outcomes generated by the students, and to the teacher (e.g. to improve his/her teaching practice).

In IBL, the main orchestrating challenge is to combine structure and guidance with the freedom of exploring required by the method [16]. Thus, teachers play an essential role in explaining the inquiry process, orienting learners through activities, presenting the inquiry topic and supporting student throughout the inquiry learning process [16].

There are plenty of platforms available on the web to support IBL and many of them address orchestration aspects. In terms of content, we can classify these platforms in three categories from least to most flexible in terms of resource aggregation: standalone tools such as SMILE [15], which do not allow to aggregate external resources; platforms that provide a set of proprietary applications that can be combined, e.g., GreenTouch [19], SAIL [17], and nQuire [12]; and platforms that support the integration of third-party tools, for example WISE [9], SCY [3], weSPOT [11], and Go-Lab [8].

To carry out our studies, we have chosen Go-Lab because apart from supporting IBL, aggregating rich content, and providing orchestration support, it allows to edit collaboratively, reuse and share the ILSs, which supports the complete life-cycle of the learning resource. Go-Lab provides a repository ${ }^{2}$ where teachers can find and reuse online labs, applications (a.k.a. apps) and existing ILSs. In addition, Go-Lab also offers Graasp $^{3}$, an ILS factory where teachers can reuse, modify or create ILSs from scratch.

\section{Inquiry Learning Spaces}

Figure 1 presents the different stages of an ILS. An ILS supports inquiry learning given that inquiry phases can be structured in tabs, content can be added to each phase and

\footnotetext{
${ }^{2}$ Golabz portal: http: //golabz . eu

${ }^{3}$ Graasp: http://graasp.eu
} 
scaffolding apps can be embedded. Figure 1.1 shows an ILS entitled Anamorphose conique in edition mode in Graasp. There, the teacher can add or modify resources and apps in each inquiry phase, which can also be modified and renamed. Graasp provides a Standalone View for each ILS, which can be accessed through a secret URL (accessible by clicking the Standalone View button). Figure 1.2 shows the login home screen of a Standalone View, which only requires a nickname. Once logged in, students see the ILS in the first inquiry phase as illustrated in Figure 1.3. Students can then navigate to subsequent phases through the tab-based navigation bar as depicted in Figure 1.4.

(1)

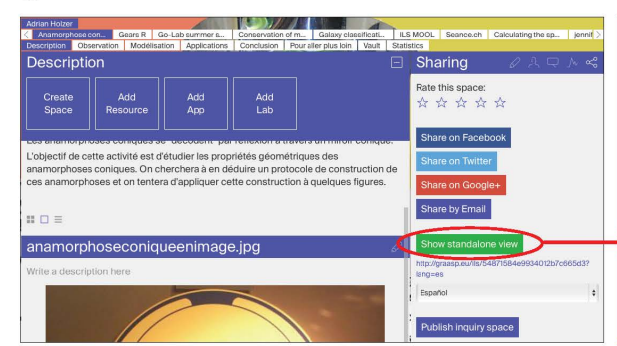

(3)
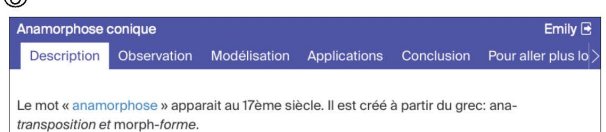

Comme l'etymologie du mot le laisse entendre, une anamorphose est une représentation très
déformée d'un objet dont on peut retrouver l'apparence normale sous un certain angle, ou vuu L'objectif de cette activité est d'étudier les propriétés géométriques des anamorphoses coniques. On cherchera à en déduire un protocole de construction de ces anamorphoses et

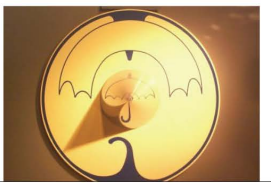

(2)

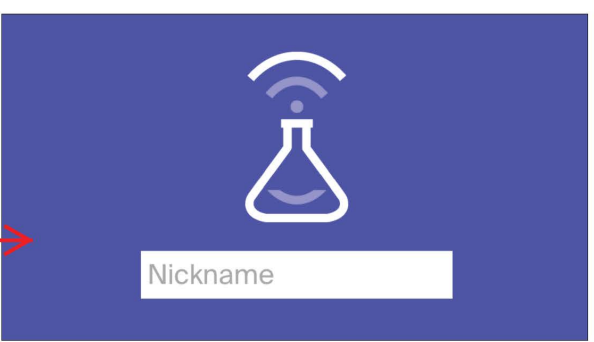

(4)

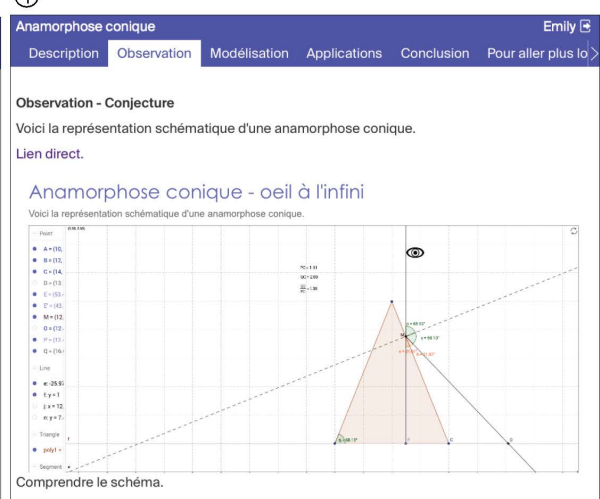

Fig. 1: Inquiry Learning Space in the Authoring view (1) and in the Standalone view $(2,3,4)$.

\section{Methodology}

Contrary to positivist methodological approaches, where all the variables are known in advance and can be controlled, in this work, the factors that impact the research questions are expected to emerge and evolve during the process [2]. Additionally, the multidisciplinary nature of TEL implies a need for mutual understanding among the involved stakeholders, demanding their active participation during the whole development cycle of TEL solutions [6]. Hence, since teachers are our target users, we involved them from the very beginning in the formulation of our proposals. These research context characteristics led us to choose Design-Based Research (DBR) [1] as the methodological framework. DBR is a systematic but flexible research approach aimed at improving educational practices through iterative analysis, design, development, and implementa- 
tion, based on collaboration among researchers and practitioners in real-world settings, and leading to contextually-sensitive design principles and theories [1].

According to the DBR criteria, our research process comprises three iterations. The main purpose of the first and second iterations is to explore the stakeholders orchestration needs in IBL scenarios using ILSs. While the first iteration focuses on teachers, the second, currently in progress, aims at gaining insight on the students' needs. The results of these iterations will lead to the definition and refinement of the solutions which will be applied in the third iteration for their evaluation.

In this paper, we report on the first DBR iteration. To identify the main orchestration needs of teachers when using ILSs, we conducted a survey-based study with 23 expert teachers to reveal what they consider as needs given their current practices. To supplement the survey and to uncover "actual" needs, we carried out 4 in-depth case studies with 2 teachers, helping us to better understand the needs that can emerge during the life-cycle of an ILS. In the following sections we describe these studies.

\section{Expert Teacher Survey}

To identify the orchestration needs that Go-Lab teachers detect when using Graasp, we conducted a survey from January 30th to March 15th, 2015. We received responses from 23 teachers, including 8 females and 15 males, between 23 and 60 years old from different European countries Cyprus, Estonia, Germany, Greece, Portugal, Spain, and Switzerland). All of them had previous experience applying IBL and using ILSs in their courses. The purposes of this questionnaire were to better understand the learning scenarios where the teachers use their ILSs and identify what additional support could help them orchestrate such scenarios.

\subsection{Learning Context}

In order to understand how the participants used their ILSs, we asked them about the characteristics of their learning contexts in terms of number of students, their age, learning mode and social level. As it is shown in Figure 2, the age range of the students is heterogeneous but the most significant group is between 15 and 16 years old. Regarding the group size, the number of the students involved in the learning scenarios varies from 12 to 140, with an average of 27 students per class. According to the responses, the teachers use their ILSs totally (47.83\%) or mainly (39.13\%) in the classroom, where the students work either individually or in small groups of 2-3 people.

\subsection{Teacher Information Needs}

To identify what information would help teachers orchestrate the learning scenario when using ILSs we asked them an open-ended question where they could express their ideas. Table 1 summarizes their answers. We have classified teacher interest on information needs along three categories: needs related to the learning design, the learning process and the learning outcomes. Table 1 shows the list of 21 needs extracted from the teachers answers, and the number of teachers mentioning a given need. Looking at the 

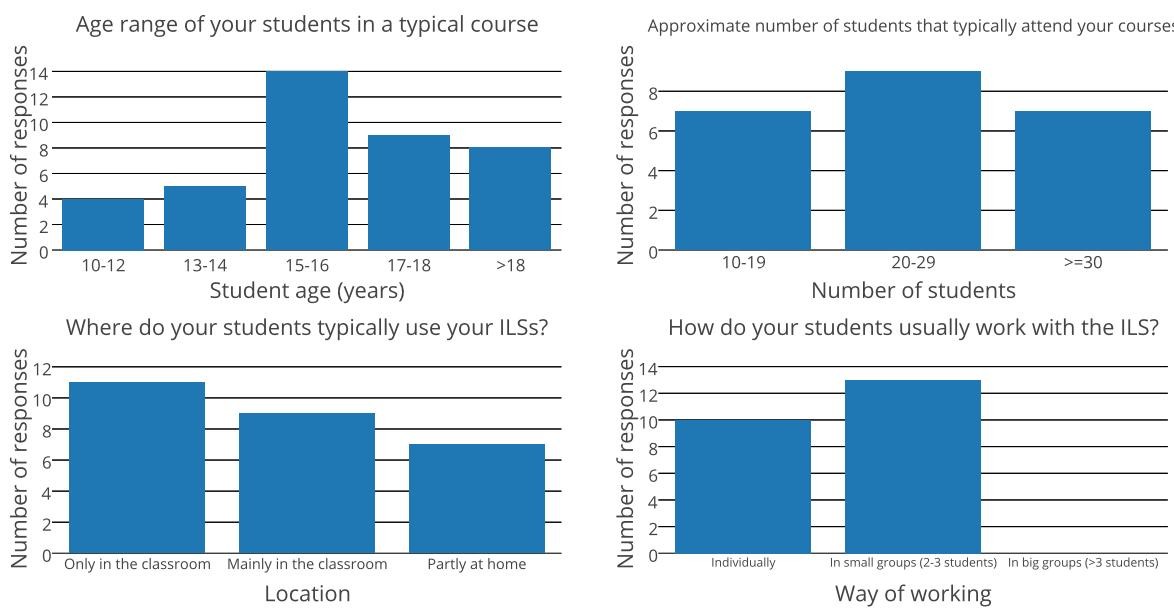

Fig. 2: Description of the surveyed teachers' learning contexts, in terms of student age, number of students, learning mode, and social level.

number of participants who mentioned needs, there are not many requests regarding the learning design $(8.70 \%)$. It appears that teachers are concerned first and foremost about the learning outcomes $(73.91 \%)$ and secondly about the learning process $(56.52 \%)$.

Learning Design. To improve the design of the ILS, the teachers identified two main needs: getting feedback from experts (e.g., other teachers, app or lab owners), and having specifications and tips from other teachers who have created/used the ILS.

Learning Process. Certain needs identified by the teachers have awareness purposes. Some of them may be covered by Learning Analytics solutions applied to the traces generated by the student's interaction with the ILS (e.g., the current phase where the students are working) and others required the student involvement (e.g., signaling of "stuck students"). This awareness information may help teachers intervene and regulate the learning scenario. Other needs serve reflection purposes, helping the teacher understand how the students use the ILS (e.g., looking at the time spent in the different parts of the ILS). Such information about the learning process may provide relevant feedback for the refinement of the ILS (e.g. by adapting the activities to the time available).

Learning Outcomes. Most of the teachers highlighted the importance of having access to students' work: reviewing the intermediate versions of the artifacts may help teachers intervene (e.g., by correcting errors or providing feedback) and regulate the scenario (e.g., suggesting the students to skip certain activities if they are running out of time); and, accessing the final versions of students' outputs enables the (summative) assessment of their work. Whenever the learning activities allow it (e.g., when using quizzes), providing students with automatic evaluation may help them identify their weak points and even offer recommendations to redirect the learning path, if needed. This information is also relevant from the teacher's point of view, since it provides an insight of the individual and whole-class comprehension of the subjects presented in the ILS. Aside from the automatic evaluation, teachers also identified the need of providing support for self, peer, and teacher evaluation of students' work in the ILS. 


\begin{tabular}{|c|c|c|c|c|}
\hline \multirow{2}{*}{ Teacher information needs } & \multirow{2}{*}{$\begin{array}{c}\text { No. } \\
\text { Teachers }\end{array}$} & \multicolumn{3}{|c|}{ Category (emphasis on ...) } \\
\hline & & Learning Design & Learning Process & Learning Outcome \\
\hline Expert feedback on the ILS design & 1 & $\mathrm{x}$ & & \\
\hline Specifications and tips from other teachers & 1 & $\mathrm{X}$ & & \\
\hline Current phase per student/ students per phase & 3 & & $\mathrm{x}$ & \\
\hline Current actions & 1 & & $\mathrm{x}$ & \\
\hline Current state & 1 & & $\mathrm{x}$ & \\
\hline Time spent (per phase, app, ILS) & 4 & & $\mathrm{x}$ & \\
\hline Followed path & 3 & & $\mathrm{x}$ & \\
\hline Visited phases & 1 & & $\mathrm{x}$ & \\
\hline Used resources, apps, labs & 2 & & $\mathrm{x}$ & \\
\hline Used devices (e.g., phones, tablets, PCs) & 1 & & $\mathrm{x}$ & \\
\hline Statistics per session (filtered) & 1 & & $\mathrm{x}$ & \\
\hline Students questions/ comments & 2 & & $\mathrm{x}$ & \\
\hline Students who required hints & 1 & & $\mathrm{x}$ & \\
\hline Stuck students & 2 & & $\mathrm{x}$ & \\
\hline Evidence of face-to-face interaction & 1 & & $\mathrm{x}$ & \\
\hline Learning outcomes & 12 & & & $\mathrm{x}$ \\
\hline Intermediate learning outcomes & 2 & & $\mathrm{x}$ & $\mathrm{x}$ \\
\hline Automatic evaluation & 5 & & & $\mathrm{x}$ \\
\hline Self-evaluation & 2 & & & $\mathrm{x}$ \\
\hline Peer-evaluation & 1 & & & $\mathrm{x}$ \\
\hline Teacher-evaluation & 1 & & & $\mathrm{x}$ \\
\hline \multicolumn{2}{|l|}{ No. indicators per category } & 2 & 14 & 6 \\
\hline \multicolumn{2}{|l|}{ No. of teachers mentioning a category } & 2 & 13 & 17 \\
\hline \multicolumn{2}{|l|}{ Proportion of interested teachers } & $8.70 \%$ & $56.52 \%$ & $73.91 \%$ \\
\hline
\end{tabular}

Table 1: Survey results regarding teacher information needs

\section{Classroom Case Studies}

To better understand the needs that emerge during the orchestration of an ILS, we conducted 4 studies with 2 teachers and their students: Alice $^{4}$, with no experience in using ILSs or IBL, and Bob, who had already used ILSs and IBL in his courses. The studies were carried out in Geneva between January and March 2015. Alice's studies took place at the École de Commerce Nicolas-Bouvier involving two groups of 7 and 11 students (18 to 20 years old) respectively. The other two studies were conducted at the Collège Sismondi with Bob and two groups of 15 and 17 students (15 to 16 years old).

The aim of these studies was to address the research question of this paper (What are the teacher orchestration needs when using ILSs?) by taking into account orchestration needs that emerge during the learning scenarios. To answer this question we used interviews and observations as main data sources. First, we interviewed the teachers before the experiments to be aware of their expertise on IBL and ILSs. Second, we collected the teachers' needs during the design of the ILS and attended the classroom to observe the learning process. Third, after the use of the ILSs, the teachers were interviewed about the problems that they faced and the orchestration needs that should be covered.

Learning Design. During the design phase, both teachers elaborated a first draft of their ILSs. In the case of Alice, she required some help to solve doubts about the ILS authoring and certain tools, as well as recommendations about apps that could satisfy her pedagogical objectives. Once the drafts of the ILSs were ready, the teachers sent them to the expert to get some feedback for the refinement of their proposals. The ILSs designed by Alice were for two maths courses. These ILSs contained theoretical

\footnotetext{
${ }^{4}$ Names have been replaced to preserve teachers' anonymity.
} 
descriptions, quizzes, Geogebra resources, a Wolfram Alpha widget ${ }^{5}$, and Google Documents where the students had to add the result of their work. The ILS designed by Bob was devoted to two of his physics courses. It was made up by a brief theoretical introduction to the topic, a few tasks to be carried out using the bibliographical resources available in the classroom, and a PhET on-line $1 \mathrm{ab}^{6}$. In the case of Bob, he refined the ILS he used in his first course to reuse it in the second one. Moreover, the teachers integrated monitoring apps in their ILSs. These apps were supposed to show them the current students per phase, the time spent per phase, and the actions registered per app.

Learning Process. In the two studies carried by Alice, the students were allowed to work individually or in groups. Since Alice was not nearby her computer, she displayed the monitoring apps using the projector, so teacher and students could see the visualizations as presented in Figure 3. She walked around, answering the questions that emerged during the learning activity. After answering the questions, Alice had a look to the apps and, according to the student distribution across inquiry phases, chose the next group to visit. At the same time, the students periodically observed the apps to compare their own progress with that of their peers. In the case of Bob, the students worked in groups of 2 to 3 sharing one computer. Since he could access the students' screens from his computer, he controlled the situation from his desk, going to the students just when the students had doubts. Bob mainly used the visualization of the active users per phase to monitor whether the students were using the ILS or not, and to be aware of the current phase where they were working on (see Figure 4). Although both teachers had designed the ILSs to be used in 90-minute, face-to-face sessions, they were also used at home because some students could not attend to the school and others did not finished the activities on time. Thus, they wanted to monitor the on-line work.

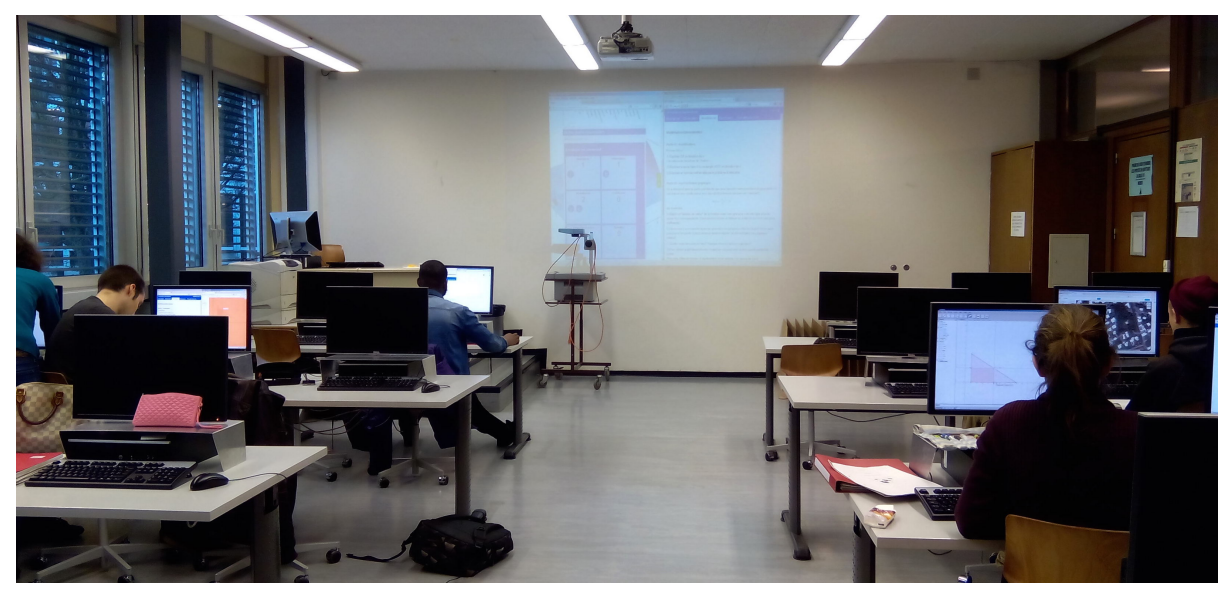

Fig. 3: Awareness information displayed for Alice and students during the first study.

\footnotetext{
5 http://www . wolframalpha.com/widgets/

6 https://phet.colorado.edu/
} 


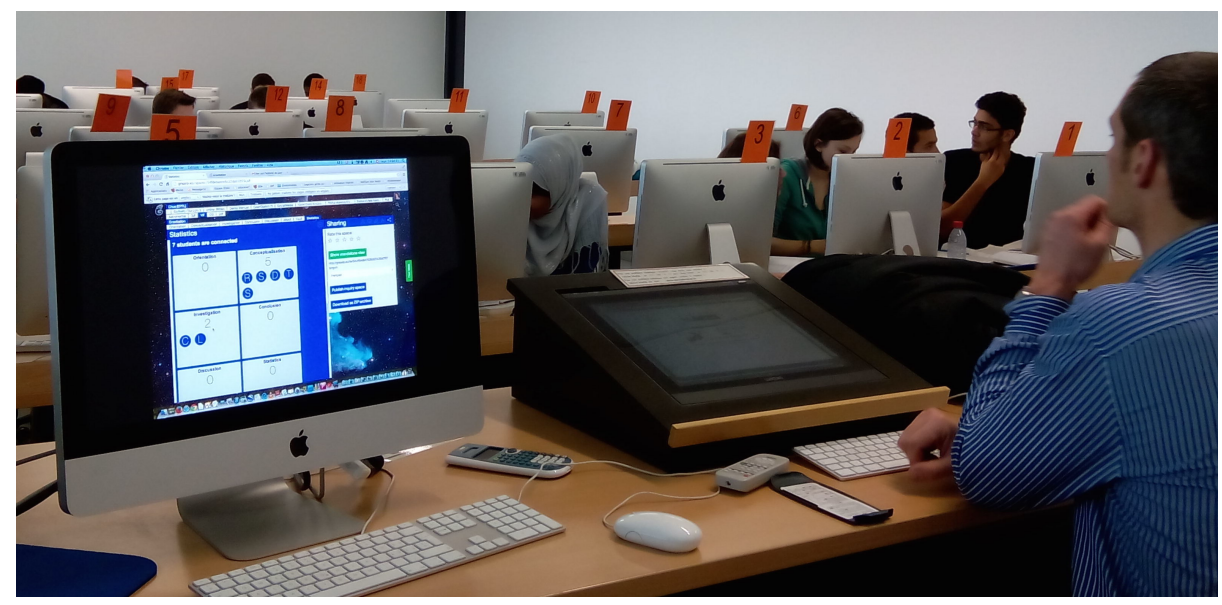

Fig. 4: Bob monitoring the students from his desktop during the second study.

For reflection purposes, the teachers considered that the "time spent per phase" could be a relevant indicator for better understanding the students' progress. Alice also mentioned that "the actions registered per app" could contribute to understand what are the apps that usually attract/discourage the students. Concerning the activity flow, the teachers detected that the students were going back and forth between phases. Therefore, Alice and Bob presented interest on analyzing the learning path, i.e. the sequence of phases and the time spent per phase, to help them improve the flow description of their ILSs. Another functionality requested by Alice was the option of visualizing the student responses, especially with the quizzes, to have an quick overview of the class.

Learning Outcomes. Both teachers agreed that their main concern was related to the assessment. According to their rubrics, around $80 \%$ of the marks focus on the learning outcomes. Therefore, they need to collect the students productions. In the case of Bob, he normally does it in paper format to have evidence sharable with other teachers, parents and students. Since certain apps and labs embedded in their ILSs did not provide storing features, they decided to collect the production of the students on paper.

\section{Discussion}

Hereafter we discuss the findings of the studies presented above along the three ILS life-cycle phases, namely learning design, learning process, and learning outcome.

Regarding the learning design, the surveys and the case studies showed that the participants were interested in having feedback from experts, as well as specifications and tips from other teachers who have created or used the ILS. Despite teachers are sometimes seen as working alone on their own projects, these findings suggest that they are actually keen to collaboratively design and discuss learning activities in a community of practice. Apart from supporting the collaborative creation of ILSs and providing social functionalities, we envision that offering recommendations based on best practices inferred from community (Go-Lab users) could guide the teachers in their designs. For 
example, applying Learning Analytics, teachers could know which apps/labs are most frequently used in each IBL phase or how many items are usually added per phase.

Multiple needs detected in the survey and the case studies were related to awareness or reflection on learning process. Although they could be addressed by means of Learning Analytics solutions such as the monitoring tools developed in the project, they should take into account the timing and the learning context. For instance, due to the lack of time to pay attention to the apps during the learning activity, the apps should provide simple information that can be interpreted in a glance to support intervention and regulation decisions. Besides, to cover those cases where teachers are not using their computers in the sessions, it is necessary to provide apps that do not require interaction (e.g., for real-time monitoring apps). Furthermore the solutions should be responsive, meaning accessible either through mobile devices or through a public display.

Finally, the survey and the studies revealed that the main teacher concern was to have access to the learning outcomes in final and intermediary versions. Although integrating third-party tools provides multiple design benefits, it also implies important challenges in terms of awareness and assessment because the technological support should integrate evidence and content coming from heterogeneous sources. Moreover, as we have seen in the case studies, some apps do not store the student's results or register the user activity. Then, no support for awareness or assessment can be provided in those cases. This issue can be mitigated by promoting the usage of open standards such as Activity Streams or Open Social. To support teachers and students in the collection of learning evidence, one potential solution could rely on the automatic generation of a student portfolio. Additionally, providing ad-hoc apps for self-assessment would help, on the one hand, students to reflect on their work and, on the other hand, teachers to focus not only on a final document but also on the learning methods the student gained.

\section{Conclusions and Future Work}

This paper investigates the orchestration needs of teachers using ILSs through a survey to 23 expert teachers and 4 authentic case studies with 2 high school teachers. The collected needs have pointed to three main conclusions. First, teachers need and appreciate collaboration support for designing inquiry-based learning activities. Second, teachers request awareness and reflection tools to support and better understand the learning process as well as improve the learning design. Last but not least, the main concern of the teachers was to have access to learning outcomes in their intermediate and final versions, so that they could further guide the students and assess their work.

In the following iterations of the DBR process, we plan to explore student orchestration needs and evaluate the solutions created to support the different stakeholders.

\section{Acknowledgements}

This research is partially funded by the European Union in the context of the Go-Lab project (Grant Agreement no. 317601). This document does not represent the opinion of the European Union and it is not responsible for any usage made of its content. 


\section{References}

1. Barab, S., Squire, K.: Design-Based Research: Putting a stake in the ground. The Journal of the Learning Sciences 13(1), 1-14 (2004)

2. Brown, A.L.: Design experiments: Theoretical and methodological challenges in creating complex interventions in classroom settings. The Journal of the Learning Sciences 2(2), 141178 (1992)

3. De Jong, T., Van Joolingen, W.R., Giemza, A., Girault, I., Hoppe, U., Kindermann, J., ..., Van Der Zanden, M.: Learning by creating and exchanging objects: The SCY experience. British Journal of Educational Technology 41(6), 909-921 (2010)

4. Dillenbourg, P., Zufferey, G., Alavi, H., Jermann, P., Do-Lenh, S., Bonnard, Q., ..., Kaplan, F.: Classroom orchestration: The third circle of usability. In: International Conference on Computer Supported Collaborative Learning. vol. 1, pp. 510-517. ISLS, Hong Kong (2011)

5. Dyckhoff, A.L., Lukarov, V., Muslim, A., Chatti, M.A., Schroeder, U.: Supporting action research with learning analytics. In: International Conference on Learning Analytics and Knowledge. pp. 220-228. ACM, New York (2013)

6. Häkkinen, P.: Challenges for design of computer-based learning environments. British Journal of Educational Technology 33(4), 461-469 (2002)

7. de Jong, T., Linn, M.C., Zacharia, Z.C.: Physical and virtual laboratories in science and engineering education. Science 340(6130), 305-308 (2013)

8. de Jong, T., Sotirou, S., Gillet, D.: Innovations in STEM education: The Go-Lab federation of online labs. Smart Learning Environments 1(3) (2014)

9. Linn, M.C., Clark, D., Slotta, J.D.: Wise design for knowledge integration. Science education 87(4), 517-538 (2003)

10. Littleton, K., Scanlon, E., Sharples, M. (eds.): Orchestrating Inquiry Learning. Routledge (2012)

11. Mikroyannidis, A., Okada, A., Scott, P., Rusman, E., Specht, M., Stefanov, K., ..., Chaimala, F.: weSPOT: a personal and social approach to inquiry-based learning. Journal of Universal Computer Science 19(14), 2093-2111 (2013)

12. Mulholland, P., Anastopoulou, S., Collins, T., Feisst, M., Gaved, M., Kerawalla, L., ..., Wright, M.: nQuire: technological support for personal inquiry learning. IEEE Transactions on Learning Technologies 5(2), 157-169 (2012)

13. Prieto, L.P., Holenko Dlab, M., Gutiérrez, I., Abdulwahed, M., Balid, W.: Orchestrating technology enhanced learning: a literature review and a conceptual framework. International Journal of Technology Enhanced Learning 3(6), 583-598 (2011)

14. Roschelle, J., Dimitriadis, Y., Hoppe, U.: Classroom orchestration: synthesis. Computers \& Education 69, 523-526 (2013)

15. Seol, S., Sharp, A., Kim, P.: Stanford mobile inquiry-based learning environment (SMILE). In: World Congress in Computer Science, Computer Engineering, and Applied Computing. pp. 270-276. CSREA Press, USA (2011)

16. Sharples, M., Anastopoulou, S.: Designing orchestration for inquiry learning. In: Orchestrating Inquiry Learning, pp. 69-85. Routledge (2012)

17. Slotta, J.D., Tissenbaum, M., Lui, M.: Orchestrating of complex inquiry: Three roles for learning analytics in a smart classroom infrastructure. In: International Conference on Learning Analytics and Knowledge. pp. 270-274. ACM (2013)

18. Sutherland, R., Eagle, S., Joubert, M.: A vision and strategy for Technology Enhanced Learning. Report from the STELLAR Network of Excellence (2012)

19. Valdes, C., Ferreirae, M., Feng, T., Wang, H., Tempel, K., Liu, S., Shaer, O.: A collaborative environment for engaging novices in scientific inquiry. In: ACM International Conference on Interactive Tabletops and Surfaces. pp. 109-118. ACM (2012) 